\title{
Regimen Used to Treat Malignant Bone Marrow Neoplasm
}

National Cancer Institute

\section{Source}

National Cancer Institute. Regimen Used to Treat Malignant Bone Marrow Neoplasm. NCl Thesaurus. Code C159872.

Any regimen that can be used for the treatment of malignant bone marrow neoplasm. 